OPEN ACCESS

Edited by:

Alexandre Chemenda, UMR7329 Géoazur (GEOAZUR),

France

Reviewed by:

Chun Liu,

Chongqing University of Science and

Technology, China Huafu Qiu,

Xi'an University of Science and

Technology, China

*Correspondence:

Rong Liu

cqu_liurong@163.com

Specialty section:

This article was submitted to

Geohazards and Georisks,

a section of the journal

Frontiers in Earth Science

Received: 01 November 2021 Accepted: 27 December 2021

Published: 17 February 2022

Citation:

Zou Y, Peng B, Liu R and Fan J (2022)

A Testing Apparatus for Gas-Driven

Coal and Gas Outbursts and

its Application.

Front. Earth Sci. 9:806814.

doi: 10.3389/feart.2021.806814

\section{A Testing Apparatus for Gas-Driven Coal and Gas Outbursts and its Application}

\author{
Yunlong Zou ${ }^{1,2}$, Bo Peng ${ }^{3}$, Rong Liu ${ }^{1 \star}$ and Jinyang Fan ${ }^{1}$ \\ ${ }^{1}$ State Key Laboratory of Coal Mine Disaster Dynamics and Control, School of Resources and Safety Engineering, Chongqing \\ University, Chongqing, China, ${ }^{2}$ CCTEG Chongqing Research Institute, Chongqing, China, ${ }^{3}$ Sichuan Coal Huarong Energy Co. \\ LTD, Chengdu, China
}

In this study, a multi-physics coal and gas outburst experimental apparatus is developed to allow investigating the gas-driven mechanism behind the disaster caused by coal and gas outbursts in tectonic regions. The apparatus can simulate the coal and gas outbursts under different initial geo-stresses, gas pressures and temperatures. By integrating acoustic emission sensors in the holes on axial platens, acoustic signals from coal samples during the whole test can be monitored. A series of testability experiments were conducted on the developed apparatus to verify its performance. The damage characteristics and outburst occurrence of raw coal under different gas pressures were experimentally studied and that provided a more complete theoretical basis for coal and gas outburst. The degree of fragmentation of coal samples and the mass proportion distributions of the outburst pulverized coal after outbursts under different gas pressures were analyzed, as a reference for exploring the evolutionary characteristics of coal and gas outburst with gas-driven action.

Keywords: testing system, coal and gas outburst, gas-driven, pressure detecting, temperature detecting

\section{INTRODUCTION}

Coal and gas outburst (CGB) is one of the biggest threats to mine safety and coal production. In the past years, CGB disasters have cause thousands of casualties in Australia (Li and Saghafi, 2014; Black, 2019), China (Zhou et al., 2014; Wang et al., 2019), Ukraine and Poland (Skoczylas, 2012). There were 230 cases of fatal coal mine CGB accidents that killed 1,611 people from 2001 to 2010 in China (Chen et al., 2012). It is reported officially that coal as the most important primary energy source in China, will maintain a huge production of more than 3 billion tones in the next 30 years. Along with the ongoing exploitation, coal resources have gradually dried up in China and coal mines have been going deeper by 10-30 m every year (Fan et al., 2018; Fan et al., 2019a; Fan et al., 2020). Hargraves (Hargraves, 1983) showed that the chance of CGBs would increase with the depth and the mining progress. Deep coal explorations are always accompanied with complex geological environments, like high geo-stress and high gas pressure. A high geo-stress can destroys the coal seam easily, which will make coal fragmentation easier and even lead to a CGB accident under the action of highpressure gas accumulated within the coal mass (Liu et al., 2014; Li et al., 2018; Zhou et al., 2019a). Aside from the mechanical properties of coal, a sufficient amount of "free" high-pressure gas is considered to be a primary initial condition for CGBs occurrence (Cao et al., 2019).

Since the first recorded coal and gas outburst in France in 1834, many efforts have been made to develop an experimental apparatus for investigating the mechanism behind CGBs. By using them, a 
number of critical results have been obtained. The most existing models fall into three categories: pocket theory, dynamic theory, and multiple-factor theory (Lama and Bodziony, 1998; Guan et al., 2009). According to the pocket theory (Shepherd et al., 1981), fractured/crushed fine coal with a larger amount of high pressure gas is wrapped in intact coal with low permeability. When the crushed coal is exposed due to failure and the surrounding intact coal is broken as a result of mining activities, an outburst would occur with a high gas pressure and a rapid coal ejection. The dynamic theory (Yang et al., 2019) states that the mining-induced stress reduces the strength of the gas-filled coal, forming a tendency for coal and gas outburst. The multiple-factor theory (Beamish and Crosdale, 1998) considers the occurrence of the outburst as the result of the combined effects of several factors: gas, stress, coal property and tectonic environment.

Because of the complex conditions during the outburst process, there is not a complete theory that can accurately explain this complex phenomenon (Xue et al., 2011; Fisne and Esen, 2014). However it is generally accepted that the most important factors influencing the occurrence of coal and gas outbursts are geological structures, gas-related properties of coal seams (composition, pressure, content, sorption capacity, desorption rate), the mining-induced stress state in the coal seam, the properties and structures of coal seams (strength, porosity, and permeability) (Cao et al., 2001; Wang et al., 2013; Wang et al., 2015; Zhao et al., 2016). Geologic structures play a very critical role in the occurrence of the CGB formation. It is known that CGBs usually occur around tectonic regions (Fisne and Esen, 2014; Zhai et al., 2016; Liu et al., 2020a; Ma et al., 2021), where coal is crushed under tectonic stress, and the gas undergoes desorption and enrichment. It has been proved that the tectonic stress/geo-stress plays a role in the process of breaking the coal body, but whether it has any influence in the process of outburst is unknown. Shepherd et al. (Shepherd et al., 1981) reported that probably over $90 \%$ of disastrous coal and gas outbursts almost always occurred in narrow strongly deformed zones such as asymmetrical anticlines, hinge zones of recumbent folds and the intensely deformed zones due to strike-slip faults. Cao et al. (Cao et al., 2001) investigated four coal mines in China and found that the footwalls of the reverse fault are the most prone to trigger a coal and gas outburst. Guan (Guan et al., 2009) considered the occurrence of CGBs as one type of gas-driven eruption. In the frame of this conjecture, outbursts are caused by high gas pressure inside coal and low ambient outside pressure. The conjecture is verified in a shock-tube apparatus, where the coal is broken into pieces and pushed into the open space due to a rapid drop in gas pressure within a shock wave. This hypothesis provides a significative prospect to the research of outburst in tectonic regions.

However, the shock-tube apparatus has some deficiencies, such as the absence of both the triaxial stress acting on coal samples and the measurements of critical parameters, limiting further investigation on the gas-driven hypothesis. These deficiencies may deprive of much useful information for outbursts. For instance, the stress state of the coal seam is three-dimensional. Major CGB disasters occur frequently in tectonic regions, and eject much more coal and gas than that in other areas. The size of outburst orifice is closely related to the intensity of coal and gas outbursts. In addition, many parameters may vary in the process of outbursts (Yang et al., 2018; Liu et al., 2020 b). It is necessary to accurately detect the parameters for outbursts.

With this in mind, researchers at Chongqing University have developed a gas-driven multi-physics coal and gas outburst experimental apparatus for avoiding the above-mentioned deficiencies. This apparatus can accommodate different sizes of raw coal samples instead of molded coal (which has a totally different structure, but is used in most of the existing CGB laboratory equipment), and simulate outbursts under various triaxial stresses and gas pressures. This paper describes the designing principles, structures, and key technologies of the apparatus. A series of exemplary experiments were conducted to check the capability, reliability, and accuracy of the apparatus.

\section{MAIN STRUCTURE AND CHARACTERISTICS OF THE APPARATUS}

The multi-physics coal and gas outburst experimental apparatus consists of a loading system, a triaxial pressure chamber, a rapid pressure relief system, a temperature control system, a data acquisition system and an auxiliary system (Figure 1). The apparatus can measure temperature, stress, gas pressure, deformation, outburst intensity and monitor acoustic emission signals of the coal sample before and during the outburst. These parameters provide quantitative data for understanding the mechanism of coal and gas outburst in tectonic regions.

\section{Loading System}

Axial loading is powered by a hydraulic cylinder, which is connected to a high pressure oil pump. The confining pressure in the triaxial pressure chamber is provided by the filling hydraulic oil from another high pressure oil pump. The loading procedure is controlled by a hydraulic servo system, which can perform displacement loading, force loading and other complicated/combined loading (like cyclic loading). The largest axial force can reach $500 \mathrm{KN}$, while the confining pressure has a maximum pressure of $60 \mathrm{MPa}$.

\section{Pressure Chamber}

Pressure chamber (Figure 1D) is the place where the geo-stress and gas atmospheres for the tested briquette samples are simulated before triggering outbursts. Three mold sizes $-\phi 25 \mathrm{~mm} \times 50 \mathrm{~mm}, \phi 50 \mathrm{~mm} \times 100 \mathrm{~mm}$, and $\phi 100 \mathrm{~mm} \times$ $200 \mathrm{~mm}$-can be used in the experiment, and the size of the mold is changeable according to other factors/requirements. The pressure chamber can ascend and descend when installing/ uninstalling the samples and is connected to a flange base via 18 bolts after finishing the preparation for tests. The center of the flange base is a pedestal seat supporting the samples and transferring the load from the lower oil cylinder. The size of the pedestal seat can be adjusted according to the sample's dimension. To facilitate samples installation, a fixing plate is 


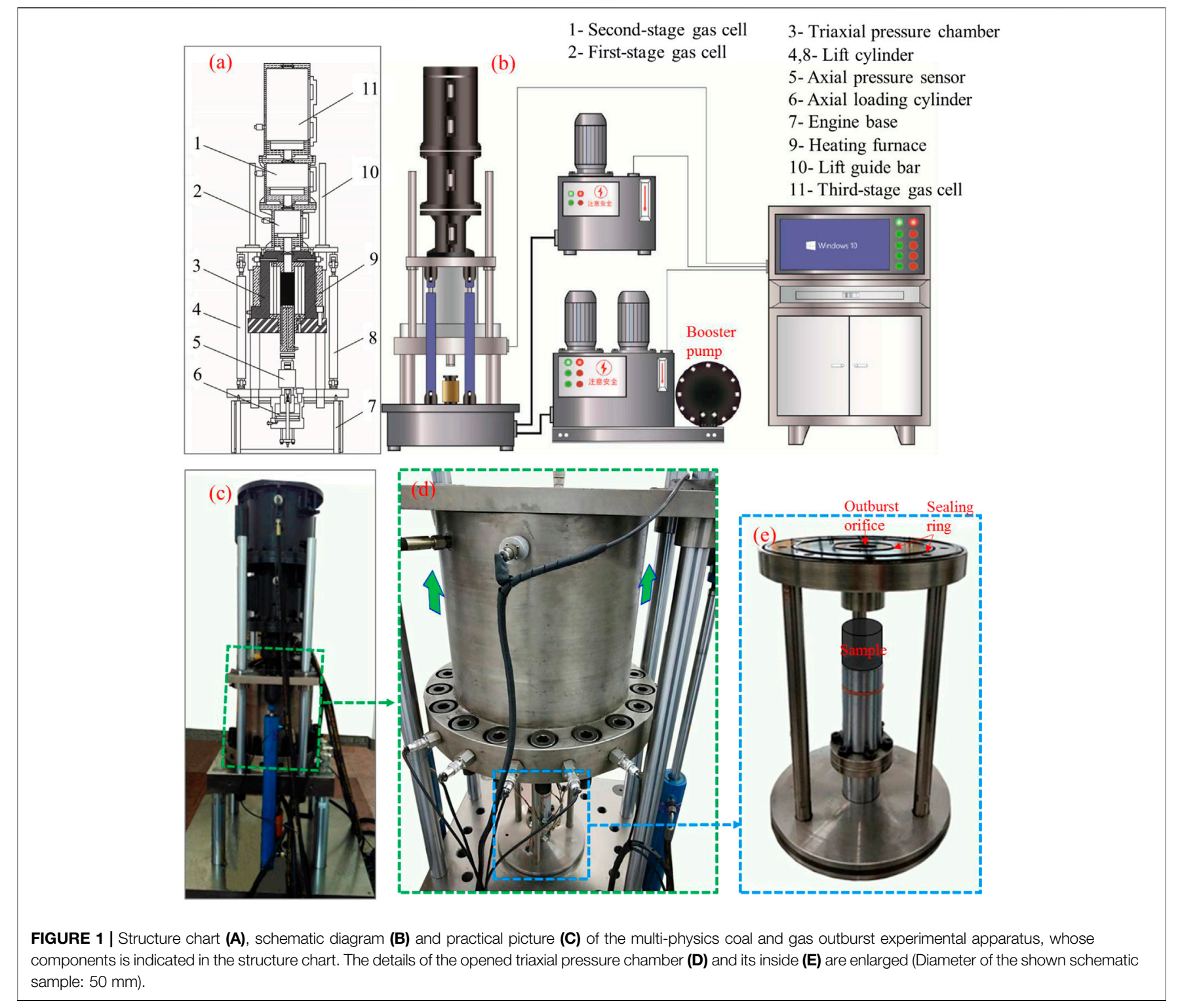

attached via three steel bars to the flange base. The fixing plate will connect with the chamber's roof when the chamber descends and get close. Between them, two homocentric rubber sealing rings (Figure 1E) are placed in grooves to ensure pressure maintaining. Similarly, at the vicinity of the flange base edge, rubber sealing rings are arranged.

The outburst orifice is located at the top of the pressure chamber and is covered by a wafer of toughened glass. The orifice has different diameters matching different size of samples. When the dimensions of the samples are $\phi 100 \mathrm{~mm} \times 200 \mathrm{~mm}$, the orifice diameter is 50 or $40 \mathrm{~mm}$. The samples of size $\phi 50 \mathrm{~mm} \times$ $100 \mathrm{~mm}$ correspond to the orifice of 30 or $20 \mathrm{~mm}$.

\section{Rapid Pressure Relief System}

The rapid pressure relief system (Figure 2) is used to quickly release the gas within the coal, and thus induce the CGB phenomenon. The system includes multistage gas cells, a piston, an annular prick knife and an oil cylinder. The gas cells are located on the pressure chamber and are connected with bolts. The annular prick knife (Figure 2C1) is located at the bottom of the gas cell and above the outburst orifice. Normally the annular prick knife remains out of touch with the toughened glass wafer. When triggering outbursts, the prick knife will move down and break the toughened glass wafer, and then release the gas. Since the toughened glass is very brittle and its rupture is instantaneous, the gas release therefore can be considered rapid.

On the premise of security, a transparent window made of toughened glass (the yellow box in Figure $\mathbf{2 B}$ ) is open on the lateral wall for the observation of outbursts (there are two transparent windows in the lateral wall. One to shine light into the cell, and one to observe). The largest gas pressure that the pressure cell can bear is $4 \mathrm{MPa}$. The multistage pressure cells (Figures 1B,C) are set up as required and different volumes of pressure chamber can be installed to change the outburst 


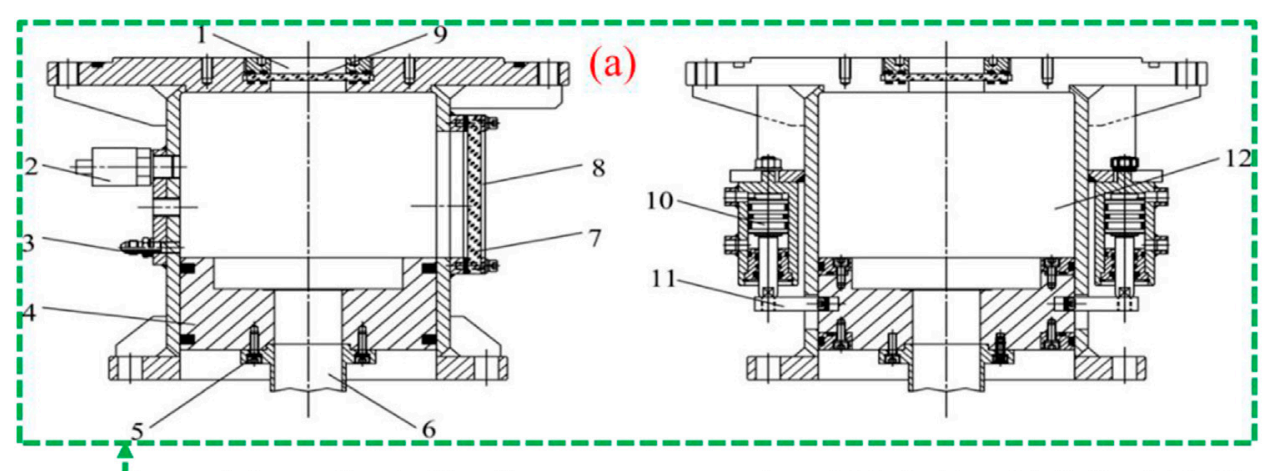

1-second-stage outburst orifice; 2- gas pressure sensor; 3-gas inlet; 4-piston; 5-bolt; 6- prick knife;

7, 9- toughened glass; 8- pressing plate; 10- oil cylinder; 11- connection plate; 12- gas cell

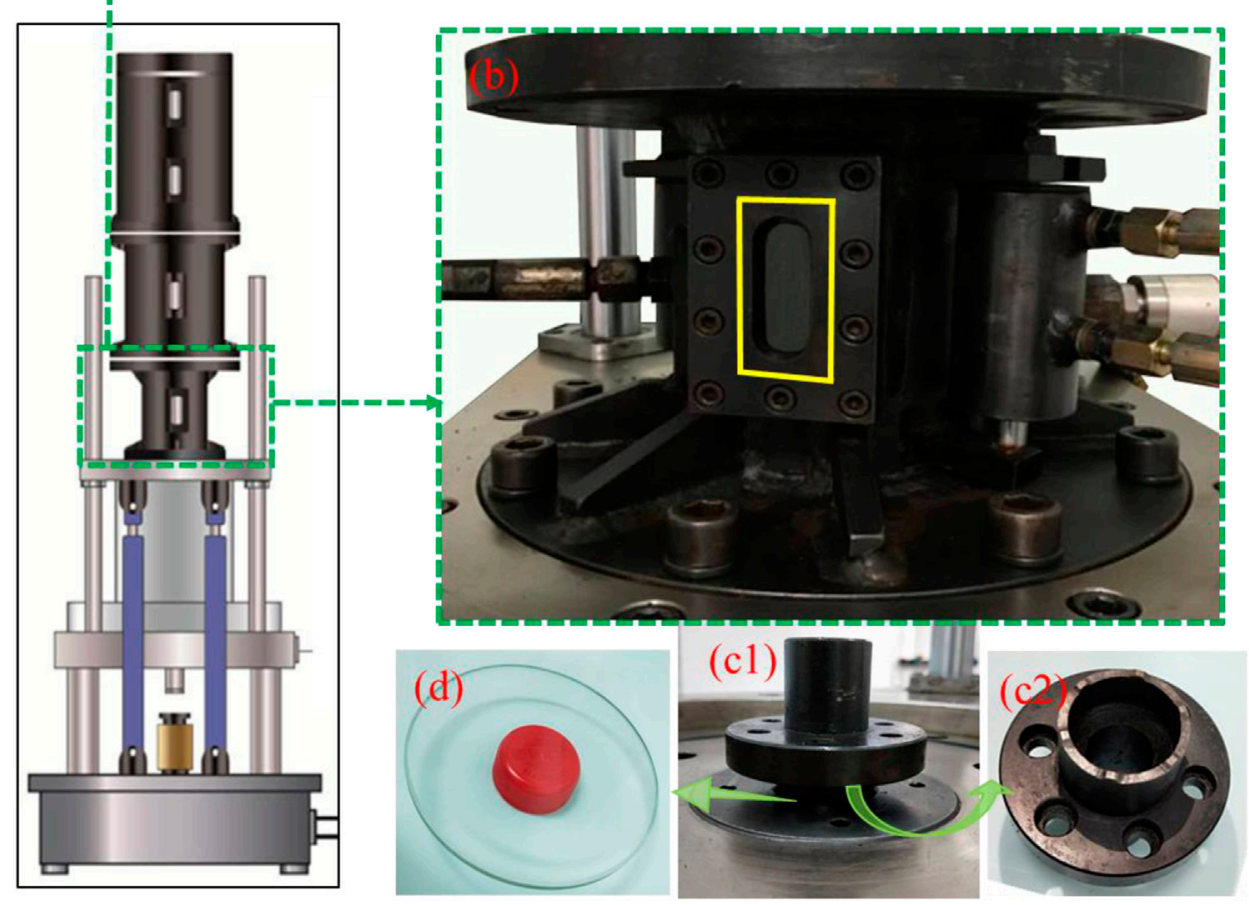

FIGURE 2 | Rapid pressure relief system. Structure diagram (A) and practical picture (B) of the first-stage gas cell; the prick knife (C1) is installed in the outburst orifice of the triaxial pressure chamber above the toughened glass (D). The bottom of the prick knife is shown in (C2), which will hit and break the toughened glass driven by the pressing plate and the oil cylinder.

intensity. The experiment may fails at times because only a few narrow cracks/slits will be created on the toughened glass wafer, keeping it basically intact and leading to slow pressure relief.

The prick knife has a variety of sizes to adapt to different outburst orifices. When the outburst orifice diameter is $50 \mathrm{~mm}$, the inside diameter of the prick knife at the bottom of the pressure chamber is $50 \mathrm{~mm}$, and the orifice diameter of the fixing plate on the pressure chamber is also $50 \mathrm{~mm}$. When the diameter of the outburst orifice changes, the sizes of the two others change accordingly.

\section{Data Acquisition System}

The data acquisition system includes all types of sensors (pressure, temperature and displacement, acoustic emission sensors, et al.), data acquisition cards, an acquisition-control servo software and a computer. A pressure sensor is installed on the piston rod end of the axial loading cylinder. Using the areas of the sensor and the piston, the applied axial load can be calculated. The accurate measuring range and resolution are $0-500 \mathrm{KN}$ and $\pm 0.01 \mathrm{KN}$, respectively. The confining stress is measured by a pressure sensor installed on the pressure chamber inner wall, and its accurate range and resolution are $0-70 \mathrm{MPa}$ and $\pm 0.001 \mathrm{MPa}$. The axial displacement is measured by a linear variable differential transformer that detects the movement of the axial piston in real time. The radial strain is measured by extensometers which are fixed on the samples using chains rolled around the sample surface. Three extensometers measure the radial expansion of coal samples at the upper, middle and lower parts, respectively. The maximum elongation of the extensometers is $16 \mathrm{~mm}$, and the resolution 


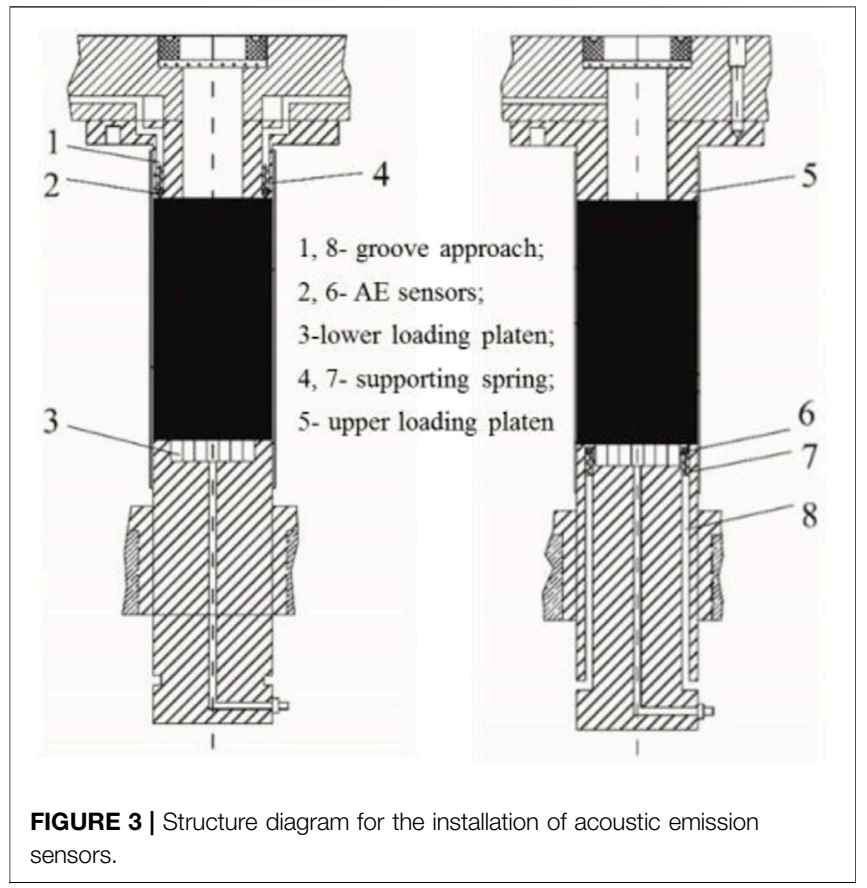

is $\pm 0.001 \mathrm{~mm}$. The temperature inside the triaxial pressure chamber is monitored by a platinum rhodium thermocouple with the accuracy range of $0-150^{\circ} \mathrm{C}$ and the resolution of $\pm 0.01^{\circ} \mathrm{C}$. Gas pressure sensors are installed in grooves on the outburst orifice wall. All the real-time data collected by sensors will be converted into electrical signals by acquisition cards, sent to the test servo control software and translated into the monitored physical information. These data would be displayed on the screen and stored in the computer or managed differently according to the monitored information. This software can store data automatically with an adjustable frequency from a small value (like 0.01 ) to thousands of $\mathrm{Hz}$, according to the experimental duration and data density requirement.

The acoustic emission (AE) monitoring system is mainly composed of $\mathrm{AE}$ detectors, miniature $\mathrm{AE}$ sensors, preamplifiers and some connecting electric wires. A mounting hole and a groove are arranged at the center of the upper and lower loading compression bars (Figure 3). Specialized miniature $\mathrm{AE}$ sensors are placed in the mounting hole and stick to one kind of coupling agent (butter) on the lower end surface of the sample. A thin electric wire passes through the groove approach and connects AE sensors to preamplifiers. The AE system can be used during the test for real-time acoustic signal detection with a frequency between $1 \mathrm{KHz}$ and $1 \mathrm{MHz}$ to analyze the outburst phenomenon and describe the evolution process of the sample fracture propagation.

\section{Auxiliary System}

This part mainly provides some auxiliary service before or after experiments (preparation phase or sample's disassembling/ installing phase). A cantilever crane is fixed between the floor and the ceiling and helps lifting the multistage gas cells, which are too heavy for manpower. A vacuum pump plays a role in vacuuming the specimen before the coal gas absorption. A dismountable heating furnace that is tightly wrapped on the triaxial pressure chamber is used to provide uniform heating on the oil and coal sample inside the chamber. The heating furnace has a thermal insulation layer on its external surface to improve the thermal efficiency and reduce the impact on the room environment. The temperature can remain constant at a preset value through the control of a temperature detect switch. The maximum temperature that the heating furnace can reach is $120^{\circ} \mathrm{C}$.

\section{PERFORMANCE CHECK ON THE APPARATUS}

\section{Checking on the Loading System}

The accuracy of the loading system is checked by comparing the MaxTest-Load software with the real output of the loading system.

The axial force checker is a standard dynamometer of grade 0.3 , model EHB-600B. The maximum axial force of the apparatus is $500 \mathrm{KN}$. The dynamometer was fixed between the compression bar and the axial piston, and axial forces were set at nine different stress levels $(50,80,100,150,200,250,300,400$, and $500 \mathrm{KN})$ in the hydraulic servo controlling software (MaxTest Load software). Each measure is read three times and the average is taken. The relative errors (shown in Figure 4A) were calculated by comparing the display from the MaxTest Load software with the values obtained from the dynamometer. It can be seen that the maximum relative error is $0.23 \%$ and the average is $0.016 \%$.

The confining pressure checker is a pressure sensor of grade 0.1 , model HM22. The maximum confining stress of the apparatus is $60 \mathrm{MPa}$. The sensor was fixed at the inner wall of the triaxial pressure chamber, and the confining stress was set at seven levels $(6,10,20,30,40,50$, and $60 \mathrm{MPa})$ in the MaxTest Load software. The output of the confining stress at each level was checked by the pressure sensor. The relative error for the confining pressure (shown in Figure 4B) was calculated with the same method as in the case of the axial stress. The relative errors (the maximum relative error is $0.25 \%$ and the average is $0.05 \%)$ fall in an acceptable range, that is, these accuracies can meet the requirements of the experimental loadings (Jiang et al., 2009).

\section{Checking on the Gas Airtightness}

The outburst orifice, the multistage gas cells and the two ends of heating shrinkable tubes (that wraps the coal sample to isolate it from hydraulic oil) should have enough airtightness during preparation and experiment. A cylindrical steel (A3 steel) column with $50 \mathrm{~mm}$ diameter and $100 \mathrm{~mm}$ length is used as "sample" in the airtightness test. The column is hollow to allow the gas to pass through the "sample" to fill/empty the outburst orifice. The airtightness test has two parts: the negative pressure test and the positive pressure test. The former is for the process of vacuuming, while the latter is for the coal absorption phase before outburst. During the test, the applied confining pressure is $1 \mathrm{MPa}$ higher than the gas pressure. 

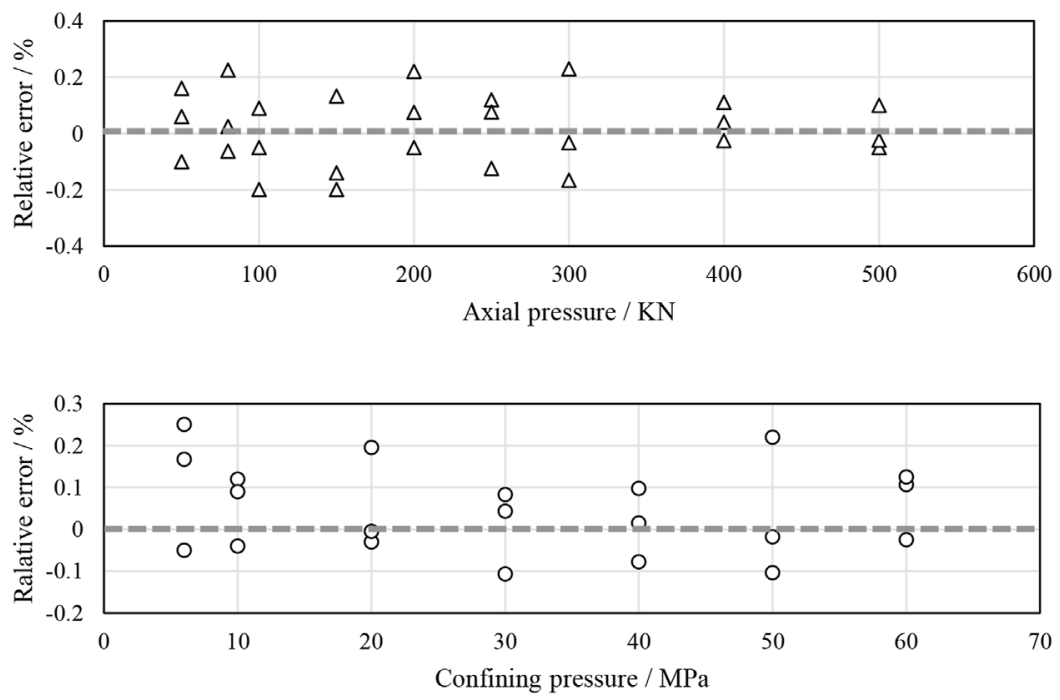

FIGURE 4 | Relative errors of the axial force and the confining pressure shown in MaxTest Load software against standard dynamometers.



FIGURE 5 | Axial pressure and count rate of acoustic emission events as a function of time during the acoustic emission monitoring with a steel column sample.

In the negative pressure test, when the gas pressure reaches $2 \mathrm{E} 1 \mathrm{~Pa}$, the valve should be closed and the vacuum pump stopped. The gas pressure showed a slight return, at $6 \mathrm{E} 1 \mathrm{~Pa}, 24 \mathrm{~h}$ later. For safety purposes, the $\mathrm{CO}_{2}$ is used to fill the "sample" during the positive pressure test. The gas pressure reaches $5 \mathrm{MPa}$ under a constant axial force of $11.78 \mathrm{KN}$ (equal to $6 \mathrm{MPa}$ ) and a confining pressure of $6 \mathrm{MPa}$. It was observed that the gas pressure remained unchanged during the $24 \mathrm{~h}$. It is suggested that the gas tightness of the apparatus can meet the requirements of the test equipment (Zhou et al., 2019b).

\section{Checking on the AE System}

Acoustic emission as transient elastic waves generated within the material due to sudden localized structure changes would be a suitable approach to track the behavior of the material without causing damage. The system accuracy for AE detection is related to its appropriate denoising threshold, which should avoid noise and also allow as much desired signals as possible. After connecting the $\mathrm{AE}$ sensors, the amplifiers and the data acquisition system altogether, we start to receive $\mathrm{AE}$ signals with the experimental equipment working as the background noises. The threshold increases gradually. When the background noise just cannot be received, the appropriate denoising threshold is obtained. The same steel column "sample" is used in simulating a uniaxial compression test (force loading method, $4 \mathrm{kN} / \mathrm{min}$ speed, to $58.91 \mathrm{KN}$ and equivalent to $30 \mathrm{MPa}$ ) to test the $\mathrm{AE}$ system performance.

Figure 5 shows the curves of AE count rate, axial pressure as a function of time during the test. The number and accumulation of 
TABLE 1 | Elemental analyses and firmness coefficient of coal samples.

\begin{tabular}{|c|c|c|c|c|c|}
\hline Coal rank & Moisture (\%) & $\begin{array}{c}\text { Ash content } \\
(\%)\end{array}$ & $\begin{array}{c}\text { Volatile component } \\
(\%)\end{array}$ & $\begin{array}{c}\text { Fixed carbon } \\
(\%)\end{array}$ & $\begin{array}{l}\text { Firmness coefficient } \\
(\%)\end{array}$ \\
\hline Bituminous coal & 1.82 & 14.23 & 11.96 & 71.99 & 0.18 \\
\hline
\end{tabular}

$\mathrm{AE}$ events both are limited. The steel strength is relatively large, the stress of $30 \mathrm{MPa}$ is far less than the yield strength of the steel sample (A3 steel's yield stress is $235 \mathrm{MPa}$ ). In the process of loading, the steel was in the elastic phase and acoustic emission mainly resulted from the tiny rub moves between the steel sample and platens. Test results show that the AE subsystem has enough sensitivity and a good performance.

\section{GAS-DRIVEN CGB EXPERIMENTS}

\section{Sample Preparation}

The experiments used raw coal core from a tectonic region (fault) of a coal mine in Chongqing China (Fengchun Coal Mine), where the CGB occurs frequently (Dai et al., 2010). Under a high tectonic stress, the coal seam in the vicinity of a tectonic (fault) region is crushed and has an unmeasurable strength. Its hardness was evaluated at $f=0.78$ with the HS method (Shore Scleroscope). The elemental analysis and firmness coefficient for the coal are shown in Table 1. Since the coal is too weak to take out samples with standard shapes (whose diameter and height are: $\phi 50 \mathrm{~mm} \times 100 \mathrm{~mm}$ ), only six samples are used to verified the performance of the apparatus. All the coal samples meet the experiment operation requirements (Fan et al., 2017; Fan et al., 2019b).

\section{Experimental Method}

The CGB experiment was carried out under different gas pressures of $1.2,1.6,1.8,2.0,2.2$ and $2.4 \mathrm{MPa}$, respectively. Carbon dioxide with a purity of $99.99 \%$ was used instead of methane for safety. To eliminate the effect of stress and verify the gas effect, a same and constant effective stress $(1 \mathrm{MPa})$ is maintained during all the tests. The experiments use a first-stage gas cell which communicates with the atmosphere and whose exit was covered by a piece of fabric to prevent the braize outflow. The inner diameter of the matched prick knife is $30 \mathrm{~mm}$.

The experiments were conducted based on the following steps. 1) After the installation of the coal sample, all the sealing parts were prepared and then the sample was vacuumed for at least $12 \mathrm{~h}$ to clean the air completely. 2) After $12 \mathrm{~h}$, all the valves were closed and the vacuum pump stopped. If the gas pressure remains constant and below $8 \mathrm{~Pa}$ within $2 \mathrm{~h}$, the next step (gas absorption) can start. 3) To avoid the effect of aeration on the sample, $\mathrm{CO}_{2}, \mathrm{CH}_{4}$ or $\mathrm{N}_{2}$ was injected slowly with a velocity of $0.2 \mathrm{MPa} / \mathrm{h}$. When the gas pressure increased to the preset value, it was kept constant for $12 \mathrm{~h}$. Then the valve was turned off. When the pressure remained unchanged for $2 \mathrm{~h}$, then the adsorption equilibrium was achieved. 4) All the preparation and stuff evacuation around the equipment were completed before triggering the outburst. The prick knife was then used to break the toughened glass and the experiment started.

\section{Results and Analyses}

Effect of Gas Pressure on the Coal Destruction

Most of experimental simulation apparatuses for CGBs have a horizontal layout (Yin et al., 2016; Ding and Yue, 2018; Wang et al., 2018; Zhou et al., 2019b), since the roadways where the CGB disasters happen frequently are always arranged along the strike direction of the coal seam, normally horizontal/near-horizontal. The horizontal layout enables the observation of the CGB process and the spatial morphology of the outburst coal. Identical phenomena were captured for both field observations and experimental tests (Jiang et al., 2009; Zhou et al., 2018):

(1) The outbursted pulverized coal has obvious sorting properties. The coal particles near the outburst exit are larger than those far from the outburst exit.

(2) The slope angle of the outburst coal is less than its natural resting angle.

(3) The larger the aeration pressure, the greater the outburst strength, and the bigger the quantity of coal particles thrown out.

Considering that the post-outburst has been well studied, the new-developed apparatus is focused on the gas-driven effect on the CGBs and thus designed with a vertical layout, which means that the outburst will propagate upwards (the effect of pressure on outburst is much greater than the effect of gravity on outburst).

When triggering the outburst, the prick knife moves down to break the toughened glass and the sensors record various physical information. Figure 6 presents the decrease of gas pressure in the first-stage gas cell under different gas pressures, which demonstrates the processes of a rapid gas pressure relief. From the presented results, it can be seen that the impact of gas pressure on the coal pulverization is significant. The characteristics of coal samples after outbursts under different gas pressures are shown in Figure 7. At a small gas pressure $(\leq 1.6 \mathrm{MPa})$, the coal remained almost intact and no pulverized coal was ejected during the rapid gas pressure relief. When the gas pressure reached $1.8 \mathrm{MPa}$, a small amount of coal was destroyed and stripped from the sample with a small cavity being formed at the upper end face of the coal sample (Figure 7A). As the gas pressure increases, more coal was destroyed and a larger cavity was formed at the upper end face of the coal sample (Figure 7B). When the gas pressure was higher than 2.0 MPa, the whole upper part of the samples was destroyed and ejected (Figures 7C-E).

As for the ejection phenomenon, coal samples behaved differently under different gas pressures. At a small pressure $(\leq 1.6 \mathrm{MPa})$, the coal remains intact and no ejection was observed. 


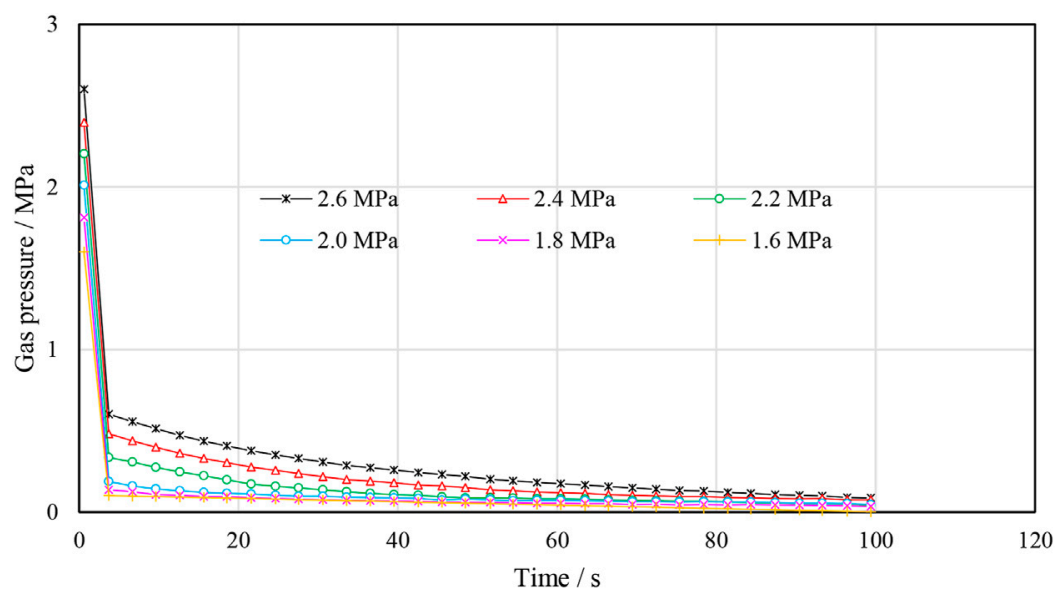

FIGURE 6 | Variation of the gas pressure in the first-stage gas cell after outbursts were triggered under different gas pressures from 1.6 to 2.6 MPa.

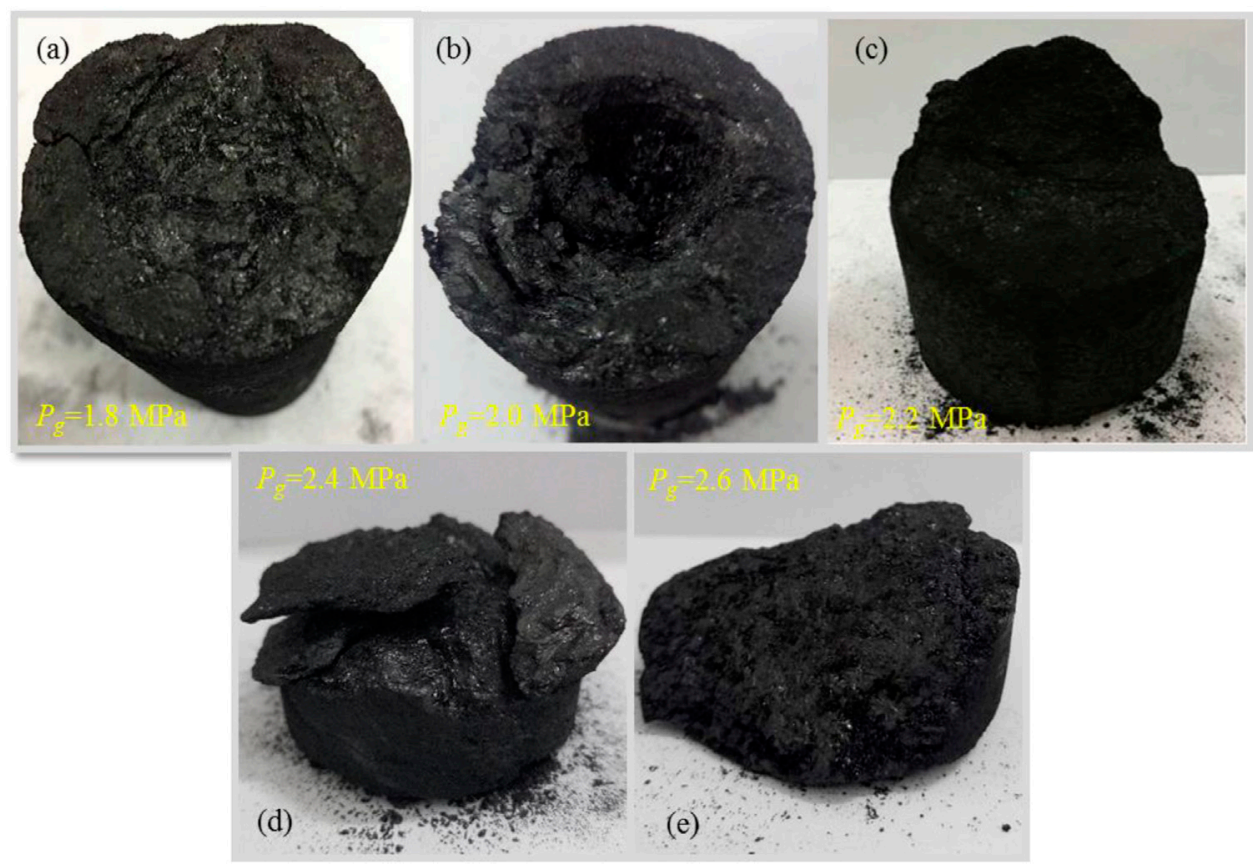

FIGURE 7|Part of coal samples maintaining a relatively complete shape after outburst under different gas pressures from 1.8 to $2.6 \mathrm{MPa}$. Coal samples for 1.2 and 1.6 MPa were basically unchanged and are not presented here.

When the gas pressure was between 1.8 and 2.0 MPa, the upper end face of the coal sample was damaged, but there was no pulverized coal in the first-stage gas cell and the coal fragments were coarser (Figure 8A). The coarser coal particles provide broad channels for gas pressure relief, which is the reason why gas is released fast. With the increase in gas pressure, the destruction degree of the coal sample increased obviously. When the gas pressure reached $2.2 \mathrm{MPa}$, a large part of the coal sample was crushed into pulverized coal, part of which remained in the heating shrinkable tube and the outburst orifice (Figure $8 \mathbf{B}$ ), and the other was ejected into the first-stage gas cell (Figure 8C). Only a small portion of the coal sample maintained a relatively complete shape (Figure 7C). At a gas pressure in the range of 2.4-2.6 $\mathrm{MPa}$, the portion of coal sample that had a relatively complete shape after outburst decreased (Figures 7D,E), and there were more (fine) pulverized coal congested at the outburst orifice and the gas cell as shown in Figures 8B,C. The fine coal powder sediment had a smaller porosity, thus decreasing the permeability and slowing down the speed of gas pressure relief as in Figure 6. 


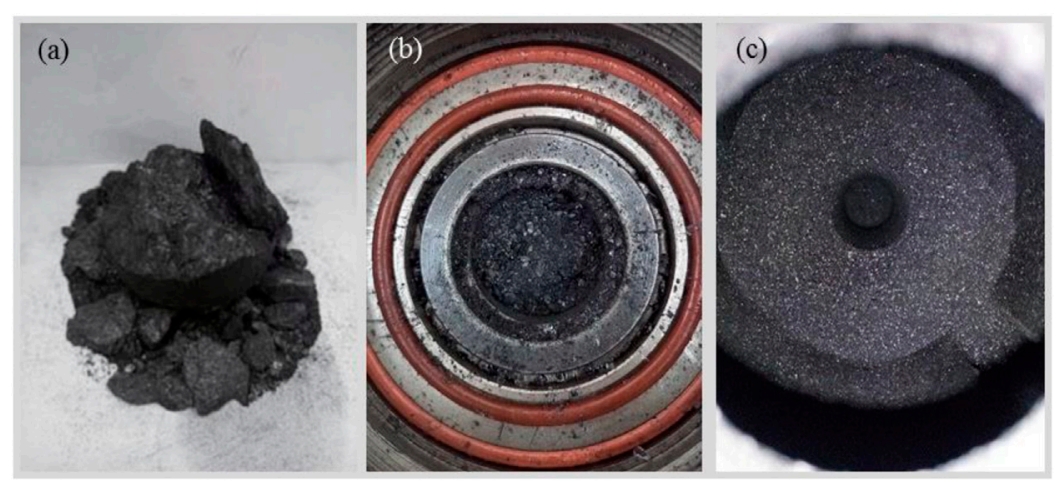

FIGURE 8|Fractured coal after outburst. (A) Fractured coal sample from the experiment under a 1.8 MPa gas pressure; (B) pulverized coal at the outburst orifice of samples from the experiment under a high gas pressure; (C) ejected pulverized coal in the first-stage gas cell of samples from the experiment under a high gas pressure.

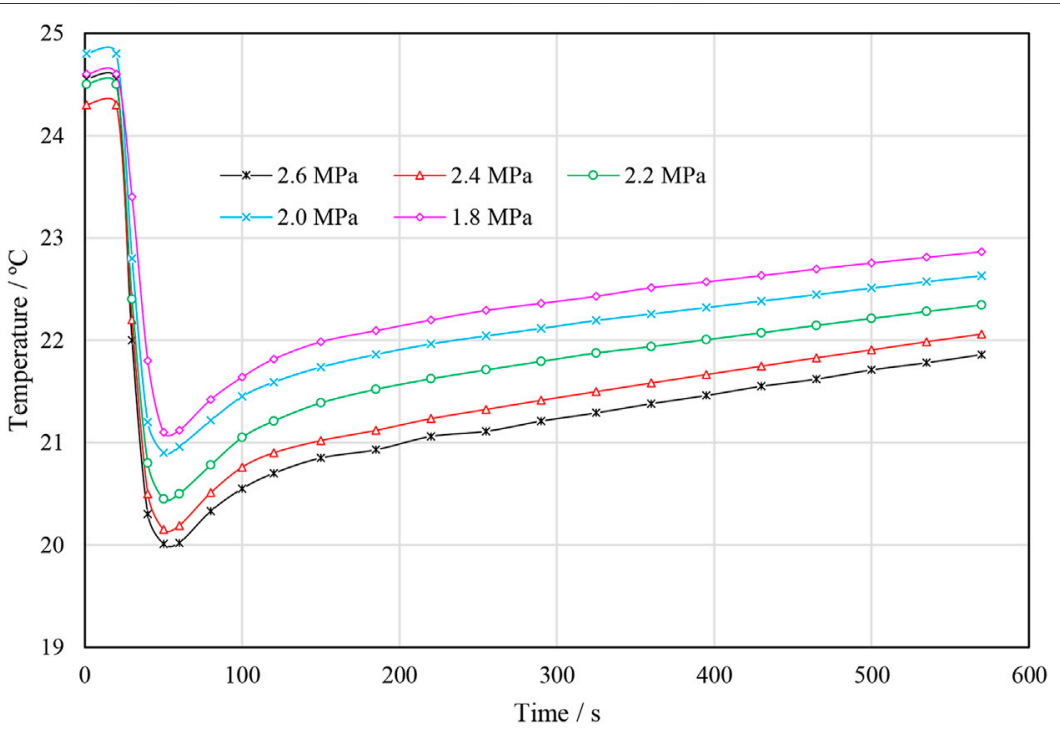

FIGURE 9 | Temperature variation of coal at the outburst orifice after outbursts with different gas pressures from 1.8 to $2.6 \mathrm{MPa}$. Since there is no fractured coal fragments around the orifice with the gas pressure at $1.2-1.6 \mathrm{MPa}$, the results is not presented.

Figure 9 shows temperature variation of the fractured/ pulverized coal at the outburst orifice. It remained constant at the room temperature during the first $20 \mathrm{~s}$, then dropped sharply, and finally went back to the normal level again. With the increase in gas pressure, the temperature drop shows a minor growth. The detected temperature decrease of $3-4^{\circ} \mathrm{C}$ is significantly smaller than its theoretical value $\left(20-30^{\circ} \mathrm{C}\right)$ calculated with an adsorption heat and an expansion work during outbursts (Liu et al., 2019a; Shu et al., 2019). That discrepancy is attributed to the long response time of the temperature sensor (however, which is inevitable for most existing temperature sensors), Pt-1000, but also to the heat dissipation from coal to the metal wall of the equipment.

\section{Effect of Gas Pressure on Outburst Intensity}

In order to quantitatively describe the fragmentation degree of the coal sample undergoing rapid gas pressure relief, the fragmentation percentage $F$ is defined as Eq. 1; (Guan et al., 2009).

$$
F=\frac{m_{1}-m_{2}}{m_{1}} \times 100 \%
$$

Where, $m_{1}$ is the coal sample mass before experiment, $m_{2}$ is the mass of the remaining coal piece that maintain a relatively complete shape after experiment. Figure $\mathbf{1 0}$ shows the percentage of fragmentation of coal samples under different gas pressures. When the gas pressure is $1.8 \mathrm{MPa}$ or $2.0 \mathrm{MPa}$, the fragmentation percentage of the coal sample is low, $F<5.1 \%$. As the gas pressure increases from 2.2 to $2.6 \mathrm{MPa}$, the coal fragmentation grows rapidly from 79.3 to $95.2 \%$. Under the condition of "low" pressure (1.8-2.0 MPa), no outburst features are observed, and the fragmentation degree of the coal sample is small. With the action of high pressure (2.2-2.6 MPa), 


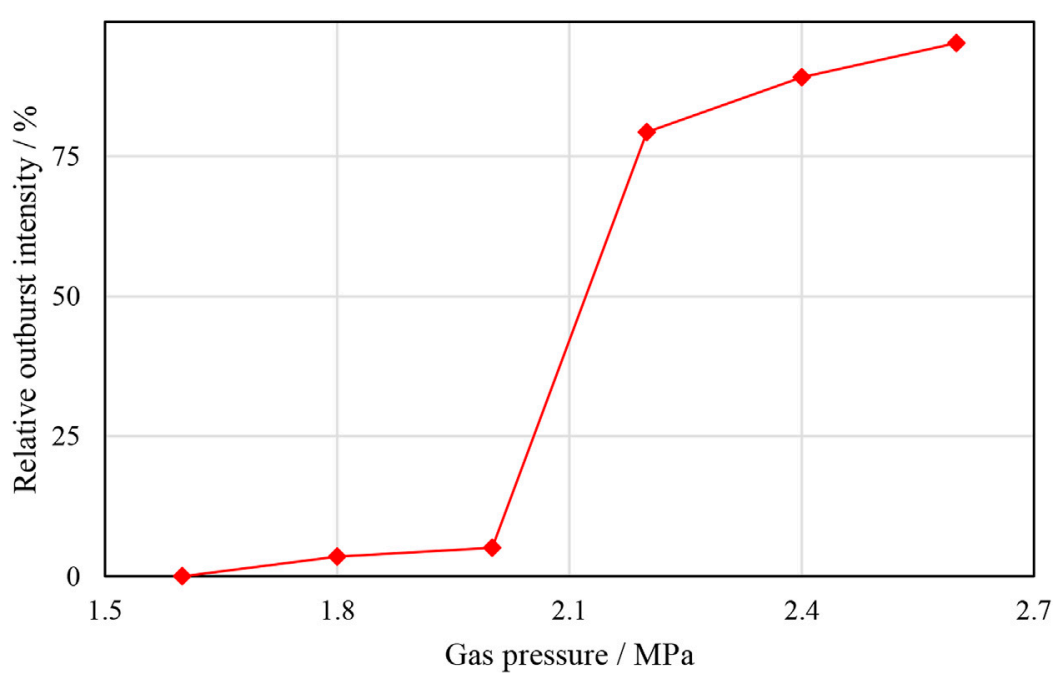

FIGURE 10 | Relative outburst intensity of the experimental coal and gas outburst under different gas pressures from 1.6 to 2.6 MPa.

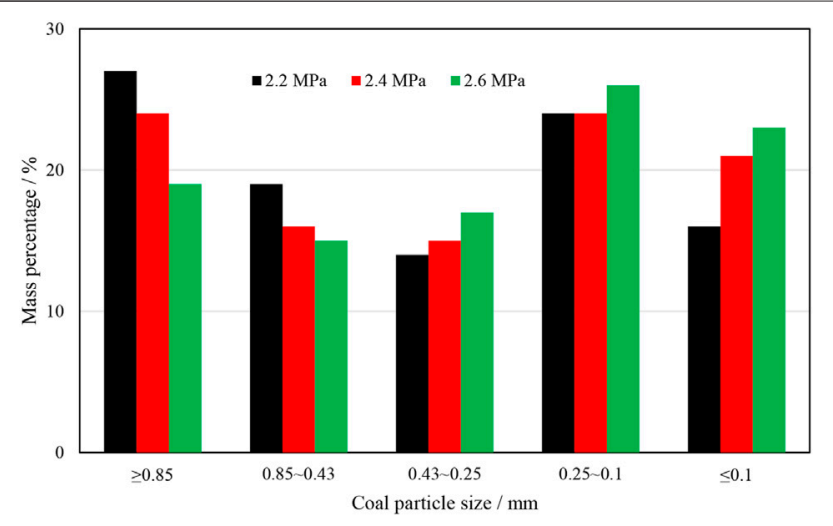

FIGURE 11 | Mass proportion distribution of the ejected pulverized coal under different gas pressures from 2.2 to $2.6 \mathrm{MPa}$. Since there is no coal ejected at a gas pressure from 1.6 to $2.0 \mathrm{MPa}$, the results is no presented.

strong outbursts occurred and a large amount of pulverized coal was ejected. In addition, the fragmentation percentage of coal samples in a high gas pressure environment grows faster than that in a low pressure environment.

CGB is a kind of strong mine dynamic phenomenon, which always comes with massive pulverized coal (or fine coal powder) ejected (Yin et al., 2016). In the present experiments, although some coal samples were destroyed under the effect of a "low" gas pressure, no pulverized coal was injected into the first-stage gas cell. Therefore, the outburst intensity was defined to indicate the CGB, including the absolute outburst intensity (the mass of ejected pulverized coal during outburst) and the relative outburst intensity (the portion of the ejected pulverized coal powder).

At a "low" gas pressure $(\leq 2.0 \mathrm{MPa})$, the outburst intensity is almost zero. The absolute and relative outburst intensities for the gas pressure of $2.2 \mathrm{MPa}$ are $87.6 \mathrm{~g}$ and $35.3 \%$, respectively. While they are $110.5 \mathrm{~g}, 126.1 \mathrm{~g}$ and $41.1 \%, 50.2 \%$ with 2.4 and $2.6 \mathrm{MPa}$ gas pressure. The results demonstrate that for the tectonic coal from the Fengchun Coal Mine, a rapid release of a gas pressure higher than 1.6 MPa, can damage the coal mass; with the gas pressure above $2.0 \mathrm{MPa}$, the CGB may occur. Those values are much lower than that obtained with the same effective stress on raw hard/primary coal (Shu et al., 2019).

We collected the ejected pulverized coal in the first-stage gas cell, and made statistical analysis on the particle size of the outburst pulverized coal. Figure 11 shows the distinct mass proportion distributions of the outburst pulverized coal under different gas pressures. With the increase in gas pressure, the mass proportion of the outburst pulverized coal with large particles (size $>0.85 \mathrm{~mm}$ ) declines and remains at a low level, accounting for about 19-27\%. Medium particles with size between 0.25 and $0.85 \mathrm{~mm}$ in the pulverized coal do not show a clear dependency on the gas pressure. However the percentage of smaller particles $(0.25-0.1 \mathrm{~mm}$ and $<0.1 \mathrm{~mm})$ goes up with the increasing gas pressure. The pulverization effect of gas refers to the effect of coal sample being pulverized into medium and small size particles under gas action. Above analysis shows that the proportion of large particles in pulverized coal under different gas pressures keep reducing, which implies that the pulverization effect is enhanced by higher gas pressures.

During experiments, once the toughened glass is broken, the gas pressure balance is lost, a lot of gas desorbs and expands rapidly together with free gas, leading to tensile stress inside the coal mass. If the gas pressure is high enough, the caused tensile stress would damage the coal samples. That is the reason why a gas pressure higher than $1.6 \mathrm{MPa}$ can destroy/fracture coal samples and create large coal particles. As the gas pressure is higher than 2.0 MPa, the collision and friction during ejection will damage the coal particles further, creating massive medium and small particles. That is called the pulverization effect. The mass proportion of small particles $(<0.10 \mathrm{~mm})$ increases with the increase in gas pressure, suggesting that the micronization 

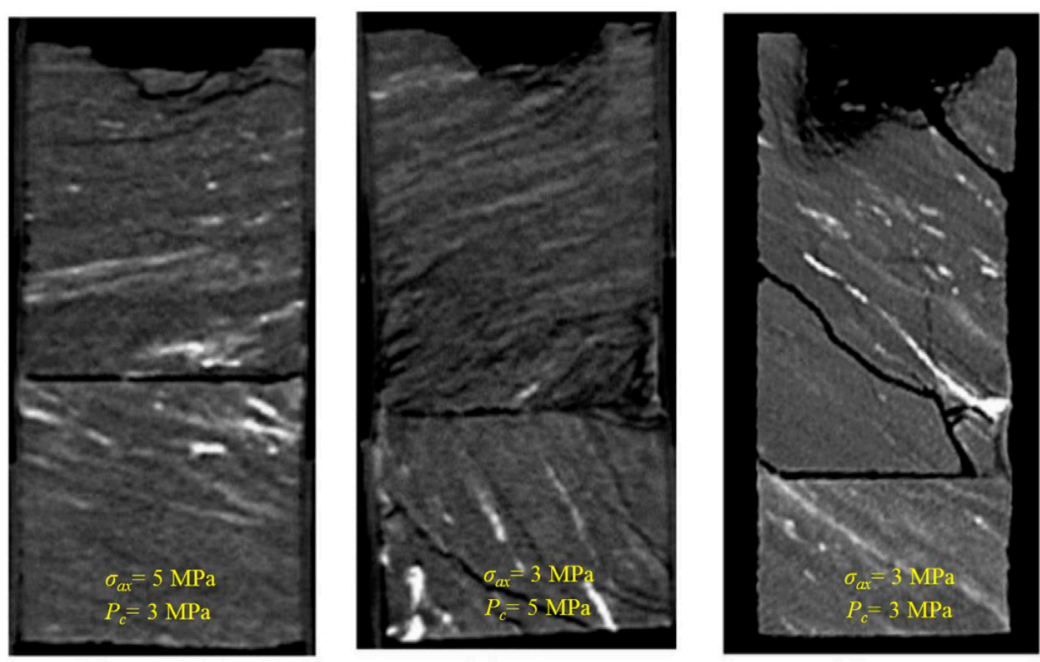

FIGURE 12 | CT (Computed Tomography) scanning images for the samples from the extra tests where the gas pressure is the same at 2.0 MPa, but the axial pressure and the confining pressure acting on the sample are different.

effect is enhanced. The literature states that the micronization effect is related to the complexity of coal-gas two-phase flow (Khatri et al., 2019). The increase in the mass proportion of small particles means that a higher gas pressure during CGB not only causes more damage, but also a more complicated two-phase flow that results in more collision and friction between coal fragments during ejection.

\section{Effect of Gas Pressure Under Different Effective Stresses}

Among the experimental results, a critical state (coal sample is damaged as in Figure 8A, with no real outburst) is obtained on the coal under a 3.0 $\mathrm{MPa}$ hydraulic pressure and a $2.0 \mathrm{MPa}$ gas pressure. Two extra experiments were conducted with the same gas pressure but a larger external stress, one under a $5 \mathrm{MPa}$ axial pressure and a $3 \mathrm{MPa}$ confining pressure, the other one under a $3 \mathrm{MPa}$ axial stress and a $5 \mathrm{MPa}$ confining pressure. The results still did not display any real outburst during the whole tests and smaller cavities at the end face were observed. A group of CT (Computed Tomography) scanning images for the samples from extra tests and the original $2.0 \mathrm{MPa}$ gas pressure test is shown in Figure 12. It illustrates less fractures inside the sample under higher confining pressure or axial pressure, which is out of most expectations in the literature (Liu et al., 2019b; Li et al., 2019) considering that geo-stress plays the most important role in CGB disasters.

Based on all the experimental results, the gas action plays a leading role in CGBs. A larger axial pressure and a confining pressure (lower than the strength of the coal material) will make the coal more compact, thus inhibiting the gas expansion and slowing down the gas seepage and desorption. It therefore can be concluded that under the conditions of constant air pressure and no strong outburst of pulverized coal ejected from the coal sample, the destruction level of the coal sample outburst decreases with the increase of axial pressure and confining pressure. In-situ stress, the greater the outburst risk, the greater the risk of this is the consensus of the critical state of coal and gas outburst. It is considered that the confining pressure will hinder the occurrence of outburst accident before the stress reaches to destroy the coal body. This is just like the phenomenon that soft coal is produced by hard coal in the process of repeated tectonic evolution. The outburst risk of soft coal is greater than that of hard coal, but after soft coal is changed into briquette with certain damage resistance through loading (extrusion) or bonding, the outburst risk of coal body will be reduced, or even less than that of hard coal. Therefore, the solidity of coal sample will be increased before the stress reaches the point of destroying coal body, which will hinder the outburst.

\section{CONCLUSION}

To confirm the gas action during CGB disasters and facilitate the use of raw tectonic coal samples, this paper developed a coal-gas outburst experimental apparatus. The design, working principle, equipment structure and basic performance parameters were introduced in this work. A series of CGB experiments under different effective stresses and gas pressures were conducted in the laboratory to verify the apparatus performance and the gasdriven effect. The results were analyzed and some conclusions were drawn.

The novelty of the test system can be summarized as follows: 1) the system can simulate the CGB process in a triaxial stress condition under gas-driven conditions, compared to Guan's shocktube apparatus. 2) The apparatus can accommodate various size of raw coal samples. 3) Multi-stage gas cells used on the apparatus can reproduce multi-outbursts to allow the observation of the outburst process. 4) Multi physical information (including the stress, strain, temperature, gas pressure and $\mathrm{AE}$ ) during outburst can be determined with this system. 
A series of tests were conducted to verify the gas-driven effect. It was noted that the rapid gas pressure relief plays a leading role during CGBs. For the tectonic raw coal from the Fengchun Coal Mine, a rapid release of a gas pressure higher than $1.6 \mathrm{MPa}$, can damage the coal mass. With a gas pressure above $2.0 \mathrm{MPa}$, the CGB may occur. A larger axial pressure and a confining pressure (but lower than the strength of the coal material) will make the coal more compact, thus inhibiting the occurrence of CGBs.

\section{DATA AVAILABILITY STATEMENT}

The original contributions presented in the study are included in the article/supplementary material, further inquiries can be directed to the corresponding author.

\section{REFERENCES}

Beamish, B. B., and Crosdale, P. J. (1998). Instantaneous Outbursts in Underground Coal Mines: An Overview and Association with Coal Type. Int. J. Coal Geology. 35 (1), 27-55. doi:10.1016/s0166-5162(97)00036-0

Black, D. J. (2019). Review of Current Method to Determine Outburst Threshold Limits in Australian Underground Coal Mines. Int. J. Mining Sci. Tech. 29, 859-865. doi:10.1016/j.ijmst.2019.03.002

Cao, J., Dai, L., Sun, H., Wang, B., Zhao, B., Yang, X., et al. (2019). Experimental Study of the Impact of Gas Adsorption on Coal and Gas Outburst Dynamic Effects. Process Saf. Environ. Prot. 128, 158-166. doi:10.1016/ j.psep.2019.05.020

Cao, Y., He, D., and Glick, D. C. (2001). Coal and Gas Outbursts in Footwalls of Reverse Faults. Int. J. Coal Geology. 48 (1), 47-63. doi:10.1016/s0166-5162(01) 00037-4

Chen, H., Qi, H., Long, R., and Zhang, M. (2012). Research on 10-year Tendency of China Coal Mine Accidents and the Characteristics of Human Factors. Saf. Sci. 50 (4), 745-750. doi:10.1016/j.ssci.2011.08.040

Dai, S., Wang, X., Chen, W., Li, D., Chou, C.-L., Zhou, Y., et al. (2010). A HighPyrite Semianthracite of Late Permian Age in the Songzao Coalfield, Southwestern China: Mineralogical and Geochemical Relations with Underlying Mafic Tuffs. Int. J. Coal Geology. 83 (4), 430-445. doi:10.1016/ j.coal.2010.06.004

Ding, Y., and Yue, Z. Q. (2018). An Experimental Investigation of the Roles of Water Content and Gas Decompression Rate for Outburst in Coal Briquettes. Fuel 234, 1221-1228. doi:10.1016/j.fuel.2018.07.143

Fan, J., Chen, J., Jiang, D., Chemenda, A., Chen, J., and Ambre, J. (2017). Discontinuous Cyclic Loading Tests of Salt with Acoustic Emission Monitoring. Int. J. Fatigue 94 (1), 140-144. doi:10.1016/j.ijfatigue.2016.09.016

Fan, J. Y., Chen, J., Jiang, D. Y., Wu, J. X., Shu, C., Liu, W., et al. (2019). A Stress Model Reflecting the Effect of the Friction Angle on Rockbursts in Coal Mines. Geomechanics Eng. 18 (1), 21-27. doi:10.12989/gae.2019.18.1.021

Fan, J., Jiang, D., Liu, W., Wu, F., Chen, J., and Daemen, J. (2019). Discontinuous Fatigue of Salt Rock with Low-Stress Intervals. Int. J. Rock Mech. Mining Sci. 115, 77-86. doi:10.1016/j.ijrmms.2019.01.013

Fan, J., Liu, W., Jiang, D., Chen, J., Ngaha Tiedeu, W., Chen, J., et al. (2018). Thermodynamic and Applicability Analysis of a Hybrid CAES System Using Abandoned Coal Mine in China. Energy 157, 31-44. doi:10.1016/ j.energy.2018.05.107

Fan, J., Xie, H., Chen, J., Jiang, D., Li, C., Ngaha Tiedeu, W., et al. (2020). Preliminary Feasibility Analysis of a Hybrid Pumped-Hydro Energy Storage System Using Abandoned Coal Mine Goafs. Appl. Energ. 258, 114007. doi:10.1016/j.apenergy.2019.114007

Fisne, A., and Esen, O. (2014). Coal and Gas Outburst hazard in Zonguldak Coal Basin of Turkey, and Association with Geological Parameters. Nat. Hazards 74 (3), 1363-1390. doi:10.1007/s11069-014-1246-9

\section{AUTHOR CONTRIBUTIONS}

$\mathrm{RL}$ and JF are responsible for providing overall ideas, $\mathrm{YZ}$ and $\mathrm{BP}$ are responsible for the research and development of physical experimental devices, RL and $\mathrm{YZ}$ are responsible for data sorting and analysis.

\section{FUNDING}

This study was supported by the Fundamental Research Funds for the National Natural Foundation of China (NSFC, grant numbers 51834003, 51904039, 51774057 and 52074048), Chongqing Postdoctoral Science Foundation (cstc2019jcyjbshX0084) and the Special Key Project of Chongqing Technology Innovation and Application Development (cstc2019jscx-tjsbX0015).

Guan, P., Wang, H., and Zhang, Y. (2009). Mechanism of Instantaneous Coal Outbursts. Geology 37 (10), 915-918. doi:10.1130/g25470a.1

Hargraves, A. J. (1983). Instantaneous Outbursts of Coal and Gas: a Review. Australas. Inst. Mining Metall. Proc. 285, 1-37.

Jiang, X., Yunqi, T., Guangzhi, Y., Shuchun, L., and Weizhong, W. (2009). Development and Application of Coal and Gas Outburst Simulation Test Device. Chin. J. Rock Mech. Eng. 27 (11), 2354-2362. doi:10.1016/S18725791(08)60057-3

Khatri, D., Gopan, A., Yang, Z., Adeosun, A., and Axelbaum, R. L. (2019). Characterizing Early Stage Sub-micron Particle Formation during Pulverized Coal Combustion in a Flat Flame Burner. Fuel 258, 115995. doi:10.1016/ j.fuel.2019.115995

Lama, R. D., and Bodziony, J. (1998). Management of Outburst in Underground Coal Mines. Int. J. Coal Geology. 35 (1), 83-115. doi:10.1016/s0166-5162(97) 00037-2

Li, G., and Saghafi, A. (2014). Comparing Potentials for Gas Outburst in a Chinese Anthracite and an Australian Bituminous Coal Mine. Int. J. Mining Sci. Tech. 24 (3), 391-396. doi:10.1016/j.ijmst.2014.03.018

Li, W., Ren, T., Busch, A., den Hartog, S. A. M., Cheng, Y., Qiao, W., et al. (2018). Architecture, Stress State and Permeability of a Fault Zone in Jiulishan Coal Mine, China: Implication for Coal and Gas Outbursts. Int. J. Coal Geology. 198, 1-13. doi:10.1016/j.coal.2018.09.002

Li, X., Li, Z., Wang, E., Liang, Y., Li, B., and Chen, P. (2019). Pattern Recognition of Mine Microseismic (MS) and Blasting Events Based on Wave Fractal Features. Fractals 26 (3), 1850029. doi:10.1142/s0218348x18500299

Liu, H., Liu, H., and Cheng, Y. (2014). The Elimination of Coal and Gas Outburst Disasters by Ultrathin Protective Seam Drilling Combined with Stress-Relief Gas Drainage in Xinggong coalfield. J. Nat. Gas Sci. Eng. 21, 837-844. doi:10.1016/j.jngse.2014.10.022

Liu, R., He, Y., Zhao, Y., Jiang, X., and Ren, S. (2020). Statistical Analysis of Acoustic Emission in Uniaxial Compression of Tectonic and Non-tectonic Coal. Appl. Sciences-Basel 10 (10), 3555. doi:10.3390/app10103555

Liu, R., He, Y., Zhao, Y., Jiang, X., and Ren, S. (2020). Tunnel Construction Ventilation Frequency-Control Based on Radial Basis Function Neural Network. Automation in Construction 118, 103293. doi:10.1016/ j.autcon.2020.103293

Liu, S., Li, X., Wang, D., Wu, M., Yin, G., and Li, M. (2019). Mechanical and Acoustic Emission Characteristics of Coal at Temperature Impact. Nat Resour Res. 29, 1755-1772. doi:10.1007/s11053-019-09562-w

Liu, W., Zhang, Z., Chen, J., Fan, J., Jiang, D., Jjk, D., et al. (2019). Physical Simulation of Construction and Control of Two Butted-Well Horizontal Cavern Energy Storage Using Large Molded Rock Salt Specimens. Energy 185, 682-694. doi:10.1016/j.energy.2019.07.014

Ma, L. H., Jiang, X., Chen, J., Zhao, Y. F., Liu, R., and Ren, S. (2021). Analysis of Damages in Layered Surrounding Rocks Induced by Blasting during Tunnel Construction. Int. J. Struct. Stab. Dyn. 21 (07), 2150089. doi:10.1142/ s0219455421500899 
Shepherd, J., Rixon, L. K., and Griffiths, L. (1981). Outbursts and Geological Structures in Coal Mines: A Review. Int. J. Rock Mech. Mining Sci. Geomechanics Abstr. 18 (4), 267-283. doi:10.1016/0148-9062(81)91192-X

Shu, C., Wang, H, Li, X, Fan, J, and Ye, X (2019). A Thermo-Hydro-Mechanical Model: Capturing the Effects of Initial Permeability and Gas Pressure on Outburst-Prone Indicators. Natural Resources Research.

Skoczylas, N. (2012). Laboratory study of the phenomenon of methane and coal outburst. International Journal of Rock Mechanics and Mining Sciences 55 (10), 102-107. doi:10.1016/j.ijrmms.2012.07.005

Wang, C., Yang, S., Yang, D., Li, X., and Jiang, C. (2018). Experimental analysis of the intensity and evolution of coal and gas outbursts. Fuel 226, 252-262. doi:10.1016/j.fuel.2018.03.165

Wang, E., Chen, P., Liu, Z., Liu, Y., Li, Z., and Li, X. (2019). Fine detection technology of gas outburst area based on direct current method in Zhuxianzhuang Coal Mine, China. Safety Science 115, 12-18. doi:10.1016/j.ssci.2019.01.018

Wang, S., Elsworth, D., and Liu, J. (2013). Mechanical Behavior of Methane Infiltrated Coal: the Roles of Gas Desorption, Stress Level and Loading Rate. Rock Mech Rock Eng 46 (5), 945-958. doi:10.1007/s00603-012-0324-0

Wang, S., Elsworth, D., and Liu, J. (2015). Rapid Decompression and Desorption Induced Energetic Failure in Coal. J. Rock Mech. Geotechnical Eng. 7 (3), 345-350. doi:10.1016/j.jrmge.2015.01.004

Xue, S., Wang, Y., Xie, J., and Wang, G. (2011). A Coupled Approach to Simulate Initiation of Outbursts of Coal and Gas - Model Development. Int. J. Coal Geology. 86 (2), 222-230. doi:10.1016/j.coal.2011.02.006

Yang, D., Chen, Y., Tang, J., Li, X., Jiang, C., Wang, C., et al. (2018). Experimental Research into the Relationship between Initial Gas Release and Coal-Gas Outbursts. J. Nat. Gas Sci. Eng. 50, 157-165. doi:10.1016/j.jngse.2017.12.015

Yang, W., Lu, C., Lin, B., Zhang, J., Lin, M., and Wang, H. (2019). Tunnelling Outburst Potential Affected by Mechanical Properties of Coal Seam. Tunnelling Underground Space Tech. 83, 99-112. doi:10.1016/j.tust.2018.09.035

Yin, G., Jiang, C., Wang, J. G., Xu, J., Zhang, D., and Huang, G. (2016). A New Experimental Apparatus for Coal and Gas Outburst Simulation. Rock Mech. Rock Eng. 49 (5), 2005-2013. doi:10.1007/s00603-015-0818-7

Zhai, C., Xiang, X., Xu, J., and Wu, S. (2016). The Characteristics and Main Influencing Factors Affecting Coal and Gas Outbursts in Chinese Pingdingshan Mining Region. Nat. Hazards 82 (1), 507-530. doi:10.1007/s11069-016-2195-2

Zhao, W., Cheng, Y., Jiang, H., Jin, K., Wang, H., and Wang, L. (2016). Role of the Rapid Gas Desorption of Coal Powders in the Development Stage of Outbursts. J. Nat. Gas Sci. Eng. 28, 491-501. doi:10.1016/j.jngse.2015.12.025
Zhou, A., Fan, L., Wang, K., and Elsworth, D. (2019). Multiscale Modeling of Shock Wave Propagation Induced by Coal and Gas Outbursts. Process Saf. Environ. Prot. 125, 164-171. doi:10.1016/ j.psep.2019.02.026

Zhou, A., Wang, K., Feng, T., Wang, J., and Zhao, W. (2018). Effects of FastDesorbed Gas on the Propagation Characteristics of Outburst Shock Waves and Gas Flows in Underground Roadways. Process Saf. Environ. Prot. 119, 295-303. doi:10.1016/j.psep.2018.08.016

Zhou, B., Xu, J., Peng, S., Geng, J., and Yan, F. (2019). Test System for the Visualization of Dynamic Disasters and its Application to Coal and Gas Outburst. Int. J. Rock Mech. Mining Sci. 122, 104083. doi:10.1016/ j.ijrmms.2019.104083

Zhou, H., Yang, Q., Cheng, Y., Ge, C., and Chen, J. (2014). Methane Drainage and Utilization in Coal Mines with strong Coal and Gas Outburst Dangers: A Case Study in Luling Mine, China. J. Nat. Gas Sci. Eng. 20, 357-365. doi:10.1016/ j.jngse.2014.07.023

Conflict of Interest: Author YZ was employed by the company CCTEG Chongqing Research Institute

Author PB was employed by the company Sichuan Coal Huarong Energy Co. LTD.

The remaining authors declare that the research was conducted in the absence of any commercial or financial relationships that could be construed as a potential conflict of interest.

Publisher's Note: All claims expressed in this article are solely those of the authors and do not necessarily represent those of their affiliated organizations, or those of the publisher, the editors and the reviewers. Any product that may be evaluated in this article, or claim that may be made by its manufacturer, is not guaranteed or endorsed by the publisher.

Copyright (c) 2022 Zou, Peng, Liu and Fan. This is an open-access article distributed under the terms of the Creative Commons Attribution License (CC BY). The use, distribution or reproduction in other forums is permitted, provided the original author(s) and the copyright owner(s) are credited and that the original publication in this journal is cited, in accordance with accepted academic practice. No use, distribution or reproduction is permitted which does not comply with these terms. 